\title{
Patients' views of medical positioning for proctologic examination
}

This article was published in the following Dove Press journal:

Clinical and Experimental Gastroenterology

30 November 2009

Number of times this article has been viewed

\section{Ole Gebbensleben \\ York Hilger ${ }^{2}$ \\ Henning Rohde ${ }^{3}$}

'Park-Klinik Berlin-Weissensee, Innere Abteilung, Berlin, Germany; ${ }^{2}$ Institut für Biostatistik, Freiburg, Germany; ${ }^{3}$ Praxis für Endoskopie und Proktologie, Berlin, Germany
Correspondence: Henning Rohde Praxis für Endoskopie und Proktologie, Viktoria-Luise-Platz I2, 10777 Berlin, Germany

Tel +493036440226

Email mail@prof-rohde.de
Background: It is unknown which proctological position is most embarrassing to patients. Methods: Individuals consecutively referred to our outpatient clinic in order to determine the causes of anal and/or abdominal complaints were randomized to complete an unvalidated six-item questionnaire which asked for their preferred proctologic positioning either before or after a proctological examination in knee-chest position followed by inspection of the anal verge, digital examination of the anal canal, and anoscopy. A third group of patients referred for gastroscopy was asked to complete the questionnaire before being gastroscoped.

Results: One hundred seventy-eight individuals of both genders aged 16-80 years who consecutively entered our outpatient clinic were enrolled. One third in each group had never experienced any of the offered medical positionings. Most patients favored the Sims' position if they had the choice. Randomized patients favored the knee-chest position more after experiencing it compared to those without experience $(P<0.03)$. Patients favored the positions they had recently experienced irrespective of the other positions offered in the questionnaire $(P<0.05)$. Individual answers to the question 'which position do you find most embarrassing?' did not depend on sex or age at first examination or when their last examination was performed. The majority of patients $(55.2 \%-71.4 \%)$ held that no type of proctological positioning was most embarrassing to them.

Conclusions: The medical profession is authorized to use the proctological positioning that allows the most reliable anal diagnoses.

Keywords: anal bleeding, anal itch, anal pain, proctological positioning, pruritus ani, hemorrhoids, benign anal diseases

\section{Introduction}

Positioning of patients for proctological assessment when anal bleeding, itch, or pain occurs may not belong to the major fields of interest of medical doctors but it might be essential for the reliability of diagnosis. ${ }^{1,2}$ The left lateral Sims' position is said to be well tolerated, especially by aged or debilitated patients. ${ }^{3}$ Certainly it is more comfortable than the knee-chest position. It is said that patients seem to prefer the recumbent position to the knee-chest position. ${ }^{4}$ Others found that the lithotomy position seems to be less tolerated. ${ }^{5}$ Whilst diagnoses might depend on positioning, ${ }^{1,2}$ doctors argue that the patient's sense of shame is violated in other than the left lateral Sims' position. ${ }^{4,5}$ In fact doctors might be biased regarding positioning of patients for proctological examination and some may even conceal their own preferences. We asked patients with and without anal complaints what they think about positioning for a proctological examination. 


\section{Methods}

\section{Patients}

Individuals who were referred by general practitioners, physicians, gynecologists or urologists in order to determine the causes of anal and/or abdominal complaints were asked to complete an unvalidated six-item questionnaire with closedended questions, which sought information on their preferred medical positioning for proctological examination (Table 1). Patients were randomized to complete the questionnaire either before (Group A, N =60) or after (Group B, N =60) a proctological examination in knee-chest position with their body bent forward followed by inspection of the anal verge,

Table I Patients' questionnaire with given answers (Please mark items as apply)

I. Had you previously had a medical examination of your anus, vagina, penis or testicles?

- No/Yes

2. If 'YES', when was that first medical examination?

When I was:

- 5-25 years

- 26-50 years

- 51 years or older

3. When was your most recent medical examination?

When I was:

- 5-25 years

- 26-50 years

- 51 years or older

4. Have you experienced of one of the following patient positions for a medical examination?

- Yes, lying on my left with bent legs (Sims' position)

- Yes, lying on my back with lifted legs (lithotomy position)

- Yes, kneeling with bent arms (knee-chest position)

- Yes, kneeling with my body bent forward (knee-chest position with the body bent forward)

5. Which of these positions would you favor most if you could choose?

- Lying on my left with bent legs (Sims' position)

- Lying on my back with lifted legs (lithotomy position)

- Kneeling with bent arms (knee-chest position)

- Kneeling with my body bent forward (knee-chest position with the body bent forward)

- None of the above

6. Which of these positions do you find most embarrassing?

- Lying on my left with bent legs

- Lying on my back with lifted legs

- Kneeling with bent arms

- Kneeling with my body bent forward

- None of the above digital examination of the anal canal, and anoscopy. A third group (Group $\mathrm{C}, \mathrm{N}=60$ ) of patients referred for gastroscopy, and therefore not expecting and not having a proctological examination was asked to complete the questionnaire before being gastroscoped. We compared the three groups for their demographic items and their answers to the questionnaire.

\section{Literature search}

We searched PubMed from April 2006 to July 2008 and found 5,801 entries for "positioning of patients". We checked the first 1,000 titles and did not find one paper concerned with proctology. For other medical specialities, the numbers were: orthopedics $(15 \%)$, anesthesia (14\%), neurosurgery $(11 \%)$, otorhinolaryngology $(9 \%)$, cardiovascular surgery $(9 \%)$, intensive care $(8 \%)$, radiology $(8 \%)$, gastroenterology $(5 \%)$, radiotherapy (4\%), physiotherapy (4\%), ophthalmology (3\%), urology (3\%), dentology (2\%), cancer research $(1 \%)$, vascular surgery $(1 \%)$, laparoscopy (1\%), gynecology (1\%), and rehabilitation medicine $(1 \%)$. One hundred seventy-two entries were found for "patients' positioning", none for "proctological positioning", but 12 for "proctological assessment". None of these were concerned with positioning of patients for proctological examination.

\section{Statistics}

For interval-level variables one-way analysis of variance with 95\% confidence intervals and the Student-Newman-Keuls procedure as post hoc test was used for detecting homogeneity subsets. For categorical-level variables, contingency tables were analyzed with the corresponding Pearson chisquared statistic. For all analyses a significance-level of alpha $=0.05$ was used. Data were analyzed using SPSS software (version 15; SPSS Inc., Chicago, IL, USA).

\section{Ethical guidelines}

This study has been conducted in accordance with the Declaration of Helsinki (1964) with the understanding and the consent of the patients. Each patient gave written consent to participate in the study, and to take photos of their anal lesions to be presented in scientific medical journals or for educational purposes with medical students and medical doctors.

\section{Results Patients}

A total of 178 individuals of both genders aged 16-80 years who consecutively entered our outpatient clinic from July 11th, 2005, to September 30th, 2005 were enrolled. The dates of two individuals were fed twice into the PC by mistake and 
therefore taken out. Thus only 178 instead of 180 individuals have been evaluated (Table 2).

The three groups of patients are homogenous concerning demographic data with minder differences for age and nationality. The majority of patients had gained experience with the Sims' and the lithotomy position at ages 5 to 50 years, and would favor them most if they could choose. About one third in each of the three groups of individuals had never experienced any of the offered medical positionings (Table 2).

Table 2 Comparison of the demographic data of the three groups of patients and results of the questionnaire

\begin{tabular}{|c|c|c|c|c|}
\hline $\begin{array}{l}\text { Characteristics } \\
\text { of individuals }\end{array}$ & $\begin{array}{l}\text { A } \\
\text { Individuals who } \\
\text { completed the } \\
\text { questionnaire before } \\
\text { the proctologic } \\
\text { examination }\end{array}$ & $\begin{array}{l}\text { B } \\
\text { Individuals who } \\
\text { completed the } \\
\text { questionnaire } \\
\text { after proctological } \\
\text { examination }\end{array}$ & $\begin{array}{l}\text { C } \\
\text { Individuals having } \\
\text { gastroscopy only } \\
\text { and no proctological } \\
\text { examination }\end{array}$ & $P$ values \\
\hline No of individuals $(N=178)$ & 57 & 62 & 59 & \\
\hline Age (years): (mean SD) & $55.9^{\mathrm{a}}(14.9)$ & $50.5(16.3)$ & $47.9^{a}(17.5)$ & $P<0.05^{\mathrm{a}}$ \\
\hline $\operatorname{Sex}(M / F)$ & $23 / 33$; one missing & $3|/ 3|$ & $28 / 31$ & NS \\
\hline Body mass index: Mean (SD) & $25.0(4.2)$ & $25.3(3.5)$ & $25.4(5.3)$ & NS \\
\hline Non-Germans (\%) & $1.8^{\mathrm{b}}$ & 6.5 & $15.3^{\mathrm{b}}$ & $P<0.05^{b}$ \\
\hline \multicolumn{5}{|l|}{ Professions (\%) } \\
\hline Clerk & 43.9 & 33.9 & 32.2 & NS \\
\hline Pensioner & 29.8 & 27.4 & 23.7 & \\
\hline Self-employed & 8.8 & 14.5 & 15.3 & \\
\hline Workmen & 7.0 & 8.1 & 3.4 & \\
\hline Housewife & 3.5 & 6.5 & 13.6 & \\
\hline Civil servant & 7.0 & 4.8 & 1.7 & \\
\hline Student & 0.0 & 4.8 & 10.2 & \\
\hline The Six questions of the questionnaire & \multicolumn{4}{|c|}{ Answers to the questions (\%) } \\
\hline \multicolumn{5}{|l|}{$\begin{array}{l}\text { I. Had you previously had a medical exam } \\
\text { of your anus, vagina, penis or testicles? }\end{array}$} \\
\hline- Yes & 78.9 & 79.0 & 78.0 & NS \\
\hline \multicolumn{5}{|l|}{ 2. If 'YES', at what age? } \\
\hline$-5-25$ years & 44.4 & 36.7 & 43.5 & NS \\
\hline$-26-50$ & 31.1 & 42.9 & 39.1 & \\
\hline$-5 \mathrm{I}$ years or older & 24.4 & 20.4 & 17.4 & \\
\hline \multicolumn{5}{|l|}{$\begin{array}{l}\text { 3. When was your most recent medical } \\
\text { examination of this type? }\end{array}$} \\
\hline$-5-25$ years & 00.0 & 12.5 & 17.4 & NS \\
\hline$-26-50$ years & 41.9 & 37.5 & 41.3 & \\
\hline-51 years or older & 58.1 & 50.0 & 41.3 & \\
\hline \multicolumn{5}{|l|}{$\begin{array}{l}\text { 4. Have you experienced of one of the } \\
\text { following medical positions? }\end{array}$} \\
\hline - Sims' position & $4 I, I$ & 34,4 & 39,0 & NS \\
\hline - Lithotomy position with lifted legs & 39,3 & 36,1 & 40,7 & \\
\hline - Knee-chest position & 05,4 & 06,6 & 06,8 & \\
\hline $\begin{array}{l}\text { - Knee-chest position with patients } \\
\text { body bent forward }\end{array}$ & 08,9 & 13,1 & 01,7 & \\
\hline - Not with any of these positions & 35,7 & 36,1 & 32,2 & \\
\hline
\end{tabular}


Table 2 (Continued)

\begin{tabular}{|c|c|c|c|c|}
\hline \multirow{2}{*}{$\begin{array}{l}\text { The Six questions of the questionnaire } \\
\text { 5. Which of these positions would you favor } \\
\text { most? }\end{array}$} & \multicolumn{3}{|c|}{ Answers to the questions (\%) } & \multirow[t]{2}{*}{$P$ values } \\
\hline & & & & \\
\hline - Sims' position & 67.3 & 63.2 & 68.5 & \\
\hline - Lithotomy position with lifted legs & 30.8 & 35.1 & 31.5 & $P<0.05^{c}$ \\
\hline - Knee-chest position & $11.5^{c}$ & $26.3^{c}$ & $03.7^{c}$ & $P<0.05^{b, c}$ \\
\hline $\begin{array}{l}\text { - Knee-chest position with patients } \\
\text { body bent forward }\end{array}$ & $11.5^{\mathrm{b}, \mathrm{c}}$ & $29.8^{b, c}$ & $01.9^{\mathrm{b}, \mathrm{c}}$ & \\
\hline \multicolumn{5}{|l|}{$\begin{array}{l}\text { 6. Which of these positions do you find } \\
\text { most embarrassing? }\end{array}$} \\
\hline - Sims' position & 3.6 & 6.5 & 1.7 & \\
\hline - Lithotomy position with lifted legs & 23.2 & 24.2 & 27.6 & \\
\hline - Knee-chest position & 03.6 & 4.8 & 10.3 & \\
\hline $\begin{array}{l}\text { - Knee-chest position with patients } \\
\text { body bent forward }\end{array}$ & $0.0^{\circ}$ & $11.3^{c}$ & $13.8^{c}$ & $P<0.05^{c}$ \\
\hline - None of the above & 71.4 & 59.7 & 55.2 & \\
\hline
\end{tabular}

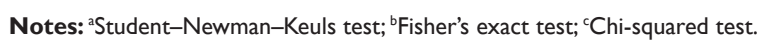

Randomized patients favored the knee-chest position with their body bent forward more after having experienced this position (Group B) compared to those without experience (Group A) with 17 of 57 patients (29.8\%) vs six of 52 patients (11.5\%) $(P<0.03$; Fisher's exact test). Preference for this position was minimal in the gastroscopy group, group $\mathrm{C}$ (Table 2).

All three groups of patients favored the positions they had recently experienced irrespective of the other positions offered in the questionnaire $(P<0.05)$. Women predominantly experienced the lithotomy position $(P<0.01)$. Individual answers to the question 'which position do you find most embarrassing?' did not depend on sex or age at first examination or on how recently their last examination was performed. But 13 of 30 women (43.3\%) and four of 28 men $(14.3 \%)$ in group $\mathrm{C}$ found the lithotomy position with lifted legs embarrassing $(P<0.01)$.

With the exception of the lithotomy position with lifted legs, patients of all three groups with no personal experience of any of the offered medical positionings in the questionnaire did not differ in their answers from patients with experience of them. The lithotomy position with lifted legs was found embarrassing by $40.9 \%$ of group A patients, but by only $15.4 \%$ of group B patients $(P<0.034)$. More group A men were embarrassed by the lithotomy position compared with group A women $(P<0.012)$. The figures for group A women compared to group B women were $25 \%$ vs $21.7 \%$, respectively. The knee-chest position with body bent forward was found to be embarrassing by $31.6 \%$ of group A patients but only $5.1 \%$ of group B $(P<0.012)$.

\section{Discussion}

Patient positioning during proctologic assessment is important for patients and doctors. We were unable to find articles where patients' wishes about positioning for proctological examinations have been evaluated. Doctors may unwittingly hide their own preferences behind alleged patients' wishes. ${ }^{3-5}$

The most striking result of our investigation is that more than half of patients $(55.2 \%-71.4 \%)$ expecting or having had a proctological examination as well as those individuals who were uninvolved in it (gastroscopy-group) held that no type of proctological positioning is most embarrassing to them. Even though the majority of individuals would favor Sims' position if they had the choice (Table 2), they give freedom to their doctors to choose that position which seems most suitable to get reliable diagnoses. Hence proctological positioning should not depend on doctors' convenience or customary rules. The key point should be the best position for the most reliable diagnoses of anal complaints.

This may differ according to the position used. The left lateral Sims' position is more comfortable and patients achieve it easily and quickly by themselves; thus the investigating physician saves time by not having to position the patient. ${ }^{3-5} \mathrm{~A}$ fundamental drawback of the knee-chest position might be that hemorrhoids could be found less frequently because of the sloping position of the patient; the large 
intestine may be pulled down towards the patients' head so that the hemorrhoids may be unable to protrude. ${ }^{1,2}$ However, it may provide a better field of view on anal and perianal surface than broadly used left lateral Sims' position, as the buttocks fall to each side, and finger tips of both hands of the investigator are free for gentle eversion of the anal skin, which may assist in more differentiated, and therefore more reliable diagnoses in good lighting ${ }^{1,6}$ (Figures 1-4).

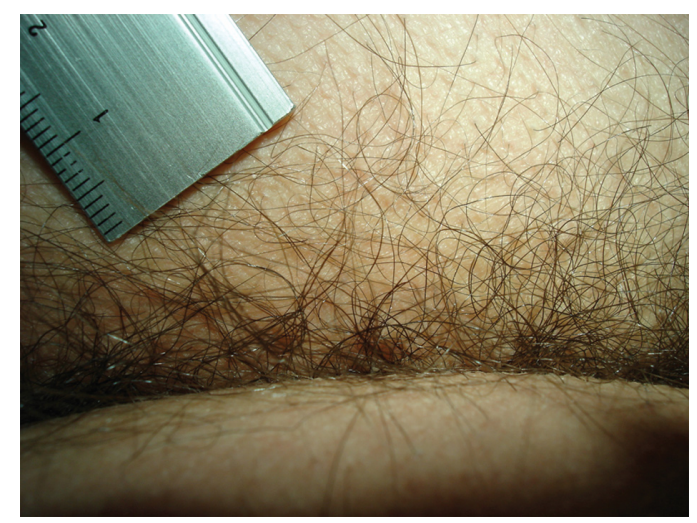

Figure I a The 42-year-old man is in knee-chest position, head left. He complained of anal itch, bleeding, and pain. Hairs are seen at the buttocks in the uneverted anal region.

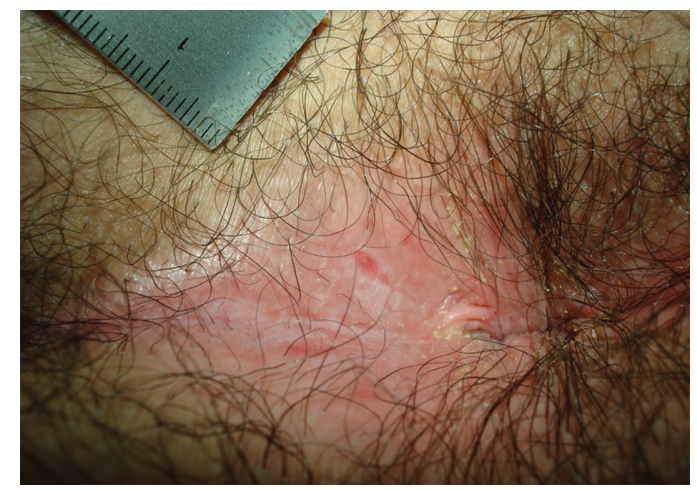

Figure I $\mathbf{b}$ The same patient after gentle eversion of the anal skin by the finger tips of both hands of the investigator. A reddened and whitish anal skin surrounded by hairs is found. The anal skin shows longitudinal superficial splits (perianal dermatitis/ anitis/pruritus ani).

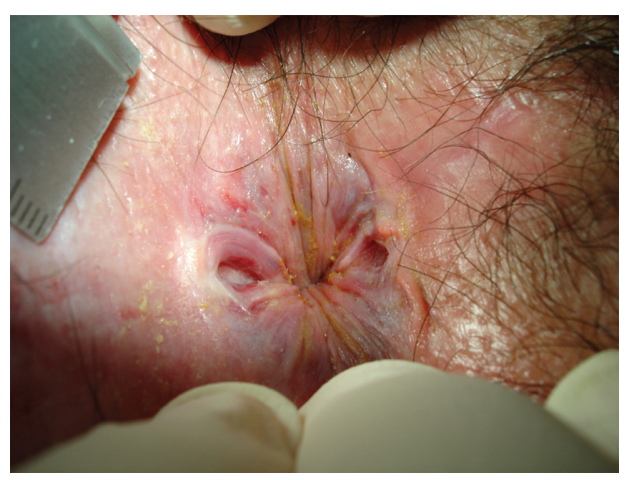

Figure I c Looking at anal verge of the same patient after strong eversion of the anal skin two chronic anal fissures (posterior and anterior) appear surrounded by a pale skin covered with partially bleeding superficial longitudinal splits.
By use of such methodology, concomitant anal findings like skin tags or a hairy anus were found in $50.6 \%$ of patients with benign anal diseases such as hemorrhoids or pruritus ani. ${ }^{2}$ Moreover concomitant anal findings were shown to play a role in the pathogenesis of benign anal diseases when patients with and without concomitant anal findings and benign anal diseases were compared $(P<0.01){ }^{2}$ Since sensitivity, specificity, and the predictive value of anal

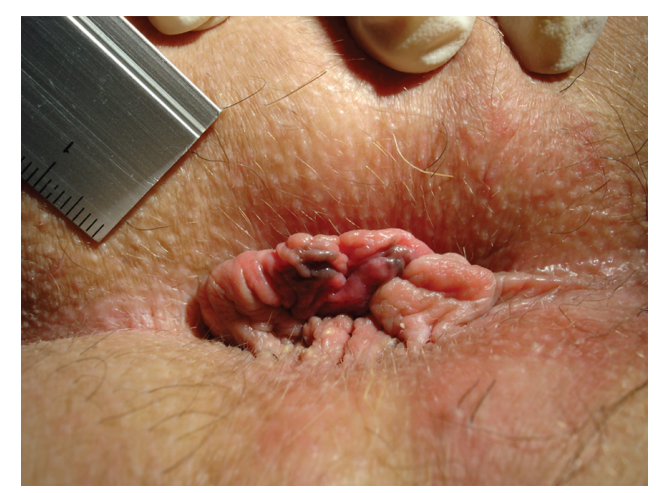

Figure 2a The 54-year-old woman is in knee-chest position, head left. She complained of anal bleeding, and pain. The anal verge is surrounded by anal tags without signs of inflammation such as edema or a reddened skin.

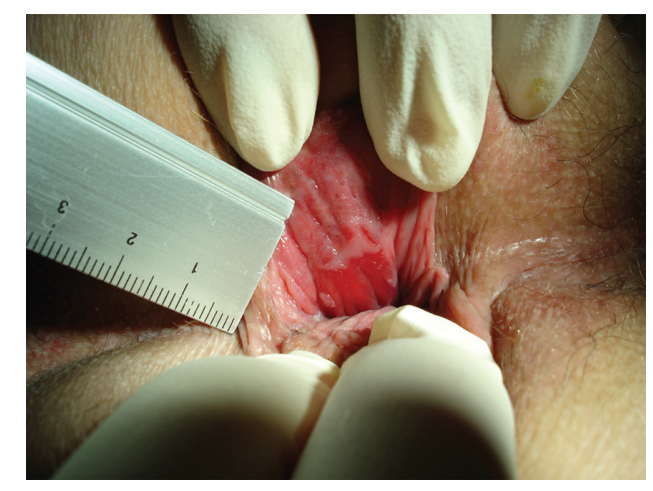

Figure $\mathbf{2} \mathbf{b}$ By gentle eversion of the anal tags by the finger tips of both hands of the investigator the dentate line appears with bright red columnar epithelium distally (hemorrhoids). Proximal the dentate line a small superficial split $3 \mathrm{~mm}$ to $4 \mathrm{~mm}$ in length within the squamous epithelium is seen (superficial fissure).

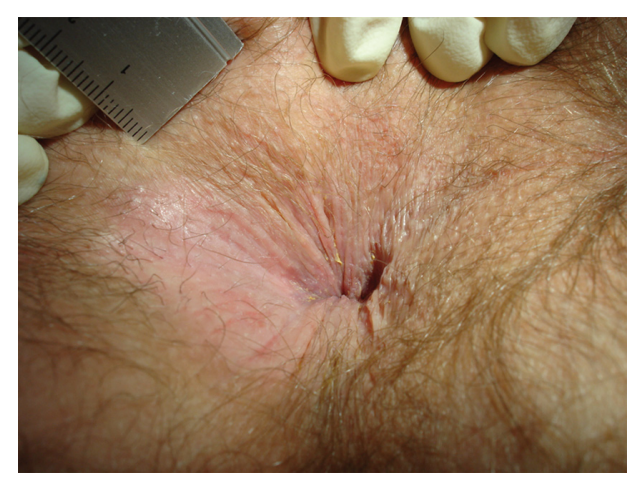

Figure 3a With gentle eversion (see the finger tips of the investigator) nothing striking is seen at the anal verge of this 23-year-old man with anal itch, pain, and bleeding when brought into the knee-chest position with his head left. 


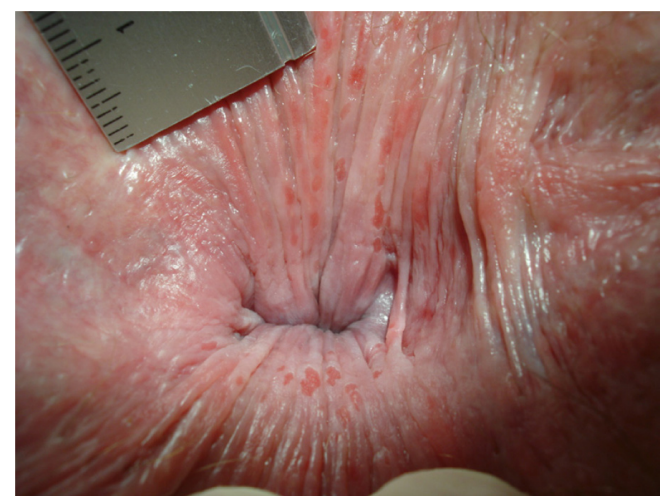

Figure 3b But if the anal skin was everted by use of the finger tips of both hands, numerous red superficial round and longitudinal gaps within the squamous epithelium proximal the dentate line are found (pruritus ani/anitis/perianal dermatitis).

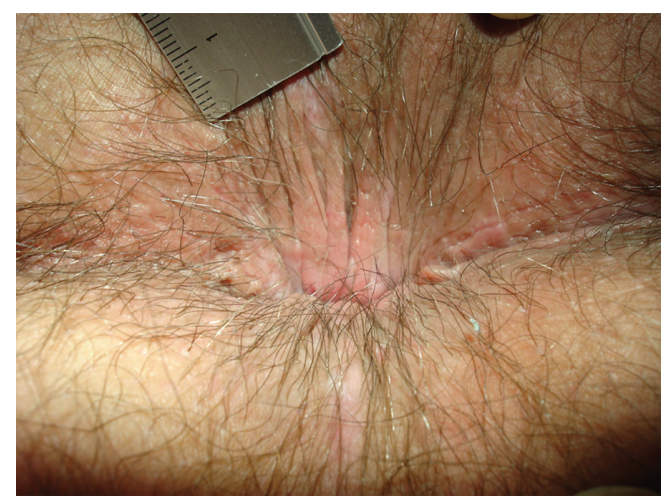

Figure 4a This 32-year-old man is in knee-chest position with his head left. He complained of anal itch at times combined with anal bleeding and pain. We see an inconspicuous anal verge covered with hairs.

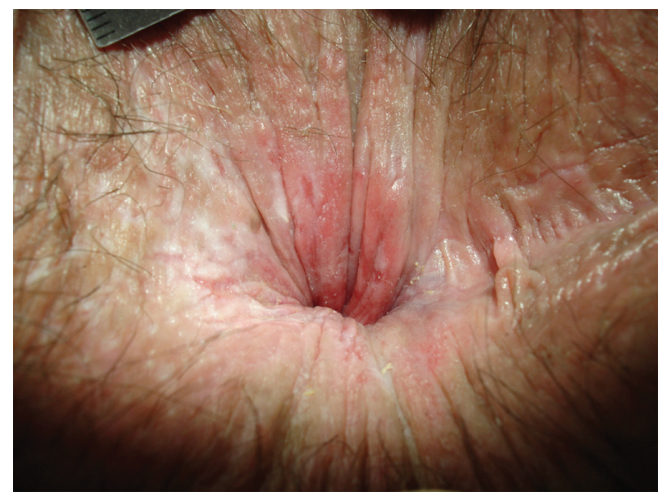

Figure $4 \mathrm{~b}$ Only by eversion of the anal skin by use of the finger tips of both hands, a whitish anal skin appears distal to the dentate line. It is covered with longitudinal superficial red splits and spots (pruritus ani/anitis/perianal dermatitis). diagnoses in different proctological positions are unknown to find out causes of anal bleeding, itch, or pain randomized clinical trials are needed to find out optimal proctologic positions for both: concomitant anal findings and benign anal diseases. Patients' answers to our questionnaire authorize doctors to do so since none of different proctological positionings are most embarrassing to them.

\section{Disclosures}

HR had the idea. All authors contributed to the design of the study. OG was responsible for literature research. OG and HR saw the patients and asked them to complete the questionnaire. Findings were ticked into a PC study documentation sheet after medical assessment of each patient. Results were discussed with all authors. YH was responsible for statistical evaluations. OG wrote the first drafts which were revised by all authors. HR wrote the final drafts. Prof. Ken Newton, edited the final draft of the manuscript. There are no conflicts of interests. The study was sponsored by the authors themselves. There were no financial or nonfinancial competing interests (political, personal, religious, ideological, academic, intellectual, commercial or any other). The authors disclose no funding sources including the writing of the manuscript and the decision to submit it for publication, data collection, analysis, or interpretation, study design, patient recruitment or any aspect pertinent to the study. None of us has been paid to write the article. All authors had full access to all the data in the study and had final responsibility for the decision to submit for publication.

\section{References}

1. Rohde H. Diagnostic errors. Lancet. 2000;356:1278.

2. Kuehn HG, Gebbensleben O, Hilger Y, Rohde H. Relationship between anal symptoms and anal findings. Int J Med Sci. 2009;6:77-84.

3. Schrock TR. Examination of the anorectum and diseases of anorectum. In: Sleisinger MH, Fordtran JS, editors. Gastrointestinal Disease, Vol 2. 5th edition. Philadelphia, PA: W. B. Saunders; 1993:1494-1516.

4. Nagle D, Rolandelli RH. Primary care office management of perianal and anal diseases. Primary Care. 1996;23:609-620.

5. Lewis TH, Corman ML, Prager ED, Robertson WG. Long-term results of open and closed sphincterotomy for anal fissure. Dis Colon Rectum. 1988;31:368-371.

6. Lockhart-Mummery HE. Non-veneral lesions of the anal region. Brit J Vener Dis. 1963;39:15-17.
Clinical and Experimental Gastroenterology

\section{Publish your work in this journal}

Clinical and Experimental Gastroenterology is an international, peerreviewed, open access journal, publishing all aspects of gastroenterology in the clinic and laboratory, including: Pathology, pathophysiology of gastrointestinal disease; Investigation and treatment of gastointestinal disease; Pharmacology of drugs used in the alimentary tract;

\section{Dovepress}

Immunology/genetics/genomics related to gastrointestinal disease. This journal is indexed on CAS. The manuscript management system is completely online and includes a very quick and fair peer-review system. Visit http://www.dovepress.com/testimonials.php to read real quotes from published authors. 